\title{
PENGARUH VARIASI TEMPERATUR PADA PROSES PERLAKUAN PANAS BAJA AISI 304 TERHADAP LAJU KOROSI
}

\author{
Dony Perdana ${ }^{1}$ \\ 1Teknik Mesin, Fakultas Teknik \\ Universitas Maarif Hasyim Latif, Sidoarjo, Indonesia \\ e-mail: dony_perdana@yahoo.co.id \\ Diterima: 31 Maret 2017. Disetujui : 23 Mei 2017. Dipublikasikan : 1 Juni 2017 \\ (C)2017 -TESJ Fakultas Teknik Universitas Maarif Hasyim Latif. Ini adalah artikel dengan \\ akses terbuka di bawah lisensi CC BY 4.0 (https://creativecommons.org/licenses/by/4.0/)
}

\begin{abstract}
ABSTRAKSI
Di dalam perkembangan industri, terutama pada bidang permesinan, metalurgi memegang peranan penting dalam pemilihan logam yang memiliki sifat-sifat mekanik maupun fisik yang sesuai dengan tuntutan produksi. Semakin luasnya tuntutan produksi logam ini. Maka sikap perancang desain dan ahli metalurgi harus mampu untuk menentukan pilihannya terhadap logam yang memperbaiki sifat-sifat logam diantaranya adalah sifat tahan korosi yang baik.

Dalam penelitian ini dilakukan proses perlakuan panas dengan variasi temperatur, yaitu pada spesimen 1 dengan $\mathrm{T}=600^{\circ} \mathrm{C}$ holding time 30 menit dan media pendingin air. Spesimen 2 dengan $\mathrm{T}=700^{\circ} \mathrm{C}$ holding time 30 menit dan media pendingin air. Spesimen 3 dengan $\mathrm{T}=800^{\circ} \mathrm{C}$ holding time 30 menit dan media pendingin air. Spesimen 4 dengan $\mathrm{T}=900^{\circ} \mathrm{C}$ holding time 30 menit dan media pendingin air. Sebab pada temperatur ini presipitasi karbida akan terbentuk. Kemudian dilanjutkan dengan mencelupkan spesimen ke dalam larutan asam sulfat $\mathrm{H} 2 \mathrm{SO} 4$.

Dari hasil penelitian didapatkan: Pada temperatur $600^{\circ} \mathrm{C}$ laju korosi sebesar 11,2208931 mpy, Pada temperatur $700^{\circ} \mathrm{C}$ laju korosi sebesar $12,6235047 \mathrm{mpy}$, Pada temperatur $800^{\circ} \mathrm{C}$ laju korosi sebesar 21,0391745 mpy, Pada temperatur $900^{\circ} \mathrm{C}$ laju korosi sebesar 30.8574559 mpy, dan pada kondisi non heat treatment laju korosi sebesar 1,40261163 mpy.
\end{abstract}

Kata kunci : temperatur, korosi, baja AISI 304

\section{PENDAHULUAN}

Metallurgy dalam sektor industri, terutama industri permesinan memegang peranan yang sangat penting. Hal ini dikarenakan bahan dasar industri permesinan adalah logam yang disesuaikan dengan sifat-sifatnya. Semakin luas dan beragam human terhadap produk industri, diperlukan pengetahuan dalam bidang metallurgy yang memadai. Penentuan keputusan pemilihan suatu jenis logam dengan keunggulan sifat-sifat tertentu yang dimilikinya serta sistematika proses produksi sangat menentukan kualitas produk dan biaya produksi.

Permasalahan yang diangkat adalah penelitian terhadap pengaruh temperatur dari baja AISI 304 terhadap laju korosi. Maka dari hal tersebut akan dapat ditentukan langkah penanggulangannya yang tepat dan sesuai dengan kasus ini, serta akan didapat penyebab kegagalannya.

\section{METODE PENELITIAN}

Baja tahan karat termasuk dalam group besi paduan dengan tingkat resistensi yang tinggi terhadap serangan kimia atau sifat tahan karat. Banyak diantara baja ini yang digolongkan secara metalurgi menjadi baja tahan karat austenit baja tahan karat ferit, baja tahan karat martensit dan baja tahan karat tipe pengerasan presipitrasi.

Sifat tahan karat ini biasanya didapat dengan cara dipadukan atau dicampur dengan minimal $11 \%$ kromium. Semakin tinggi paduan kromium dan penambahan nikel, dan beberapa elemen lain akan membuat sifat tahan karat dari stainless steel semakin baik.

Dengan penambahan kromium ini akan menyebabkan baja bersifat tahan karat, karena lapisan chrom menyebabkan permukaan pasif atau stabil, keadaan ini didapat karena chrom lebih mudah teroksidasi. Adapun dengan penambahan unsur nikel juga akan menyebabkan baja bersifat tahan karat karem unsur nikel akan mengurangi berat yang hilang akibat korosi dalam asam dan memperbaiki ketahanan korosi. Jadi baja tahan karat adalah baja paduan yang memanfaatkan keefektifan unsur $\mathrm{Cr}$ dan $\mathrm{Ni}$, dan dapat dibagi 


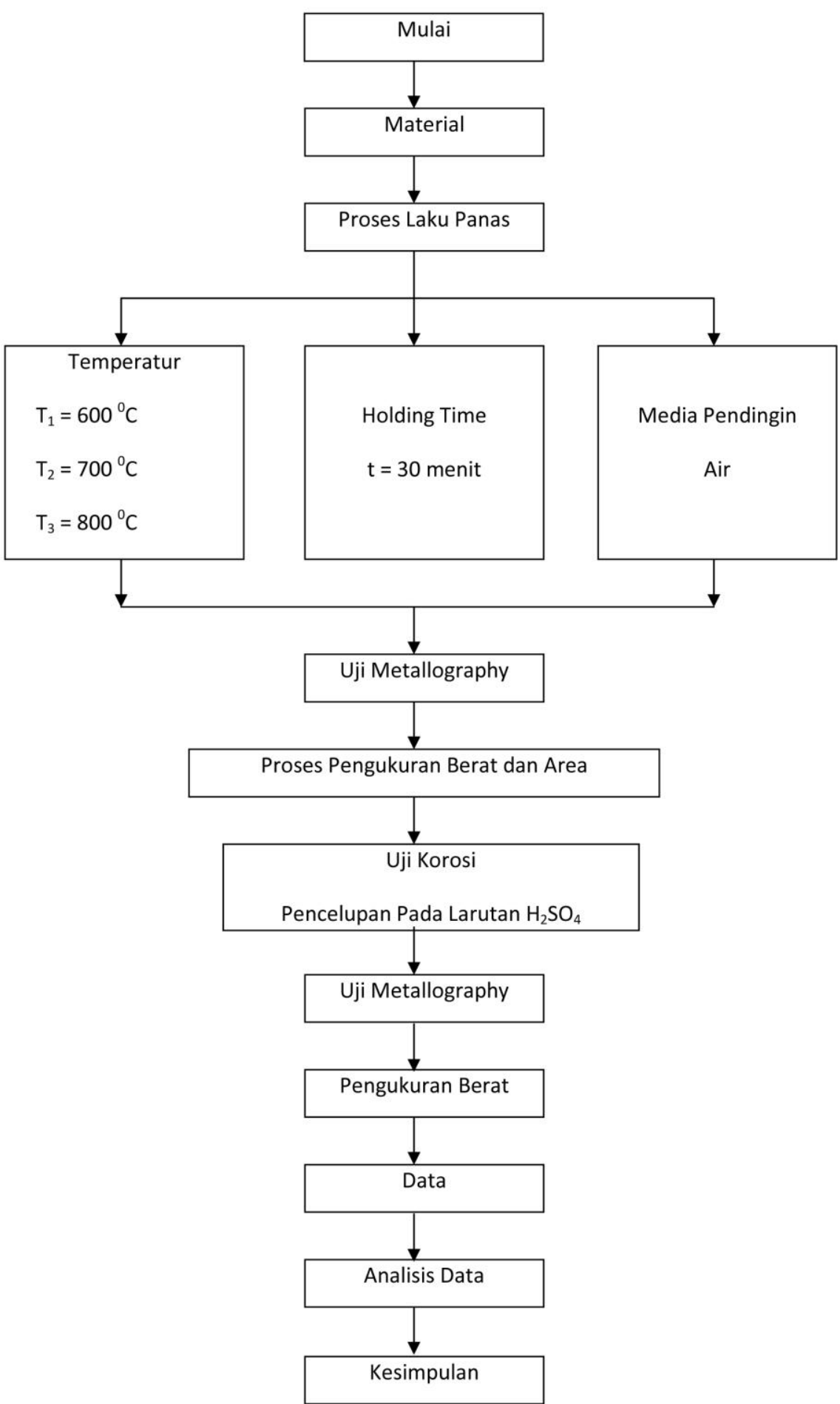

Gambar 1. Blok diagram percobaan

menjadi system $\mathrm{Fe}-\mathrm{Cr}$ yang termasuk dalam, klasifikasi

Material dasar benda kerja yang digunakan dalam penelitian ini adalah baja AISI 304 pelat dengan dimensi : $75 \mathrm{~mm} \times 75 \mathrm{~mm} \times 5 \mathrm{~mm}$.

Specimen yang digunakan dalam penelitian ini adalah proses heat treatment dan uji korosi. Spesifikasi komposisi kimianya adalah sebagai berikut :

Carbon $\quad: 0,08 \% \quad P \quad: 0,030 \%$

\begin{tabular}{llll} 
Kromium & $: 18 \%$ & Sulfur & $: 0,023 \%$ \\
Nikel & $: 8,88 \%$ & $\mathrm{~N}$ & $: 0,0490 \%$ \\
Manganese $: 2 \%$ & Silicon $: 1 \%$ & \\
kekuatan luluh & $:$ min. $30 \mathrm{Ksi}$ \\
kekuatan tarik & $:$ min.75 Ksi \\
Elongation & $: 30 \%$ \\
Reduction of area & $: 50 \%$ \\
\multicolumn{4}{c}{ Sedangkan perlakuan panas pada } \\
temperatur yang telah di tetapkan kemudian \\
menahannya beberapa saat (Holding Time) untuk
\end{tabular}


berdifusinya karbon ke dalam austenit, setelah itu didinginkan dengan cepat.

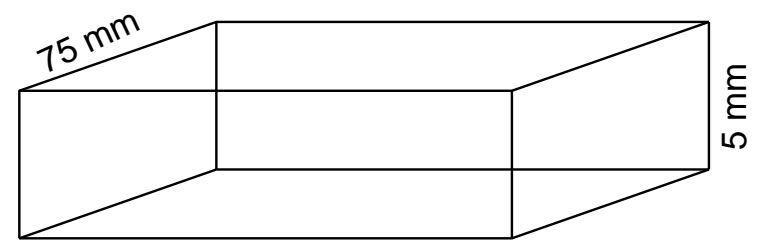

$75 \mathrm{~mm}$

Gambar 2. Dimensi pelat

Secara terperinci teknis penelitian dari proses ini adalah sebagai berikut:

1. Dalam penelitian ini terdapat beberapa variasi yaitu :

a. Temperatur austenisasi

$$
\begin{array}{lll}
\mathrm{T}_{1}=600^{\circ} \mathrm{C} & \mathrm{T}_{2}=700^{\circ} \mathrm{C} & \mathrm{T}_{3}=800^{\circ} \mathrm{C} \\
\mathrm{T}_{4}=900^{\circ} \mathrm{C} &
\end{array}
$$

b. Waktu penahanan (Holding time yang diambil adalah 30 menit).

c. Media pendinginnya adalah Air

Tabel 1. Variasi perlakuan

\begin{tabular}{|c|c|c|c|c|}
\hline $\begin{array}{c}\text { Spesimen } \\
\text { Nomor }\end{array}$ & $\begin{array}{c}\text { Jumlah } \\
\text { Spesimen }\end{array}$ & $\begin{array}{c}\text { Temperatur } \\
\text { Pemanasan }\left({ }^{\circ} \mathrm{C}\right)\end{array}$ & $\begin{array}{c}\text { Lama } \\
\text { Penahanan }\end{array}$ & $\begin{array}{c}\text { Media } \\
\text { Pendingin }\end{array}$ \\
\hline 1 & 1 & $\begin{array}{c}\text { Non Heat } \\
\text { Treatment }\end{array}$ & - & - \\
2 & 1 & $600^{\circ} \mathrm{C}$ & 30 menit & Air \\
3 & 1 & $700^{\circ} \mathrm{C}$ & 30 menit & Air \\
4 & 1 & $800^{\circ} \mathrm{C}$ & 30 menit & Air \\
5 & 1 & $900^{\circ} \mathrm{C}$ & 30 menit & Air \\
\hline
\end{tabular}

2. Pengamatan Metallography

Pengujian ini dilakukan untuk mendapatkan struktur mikro dari specimen awal (non heat treatment), setelah proses heat treatment, dan setelah uji korosi.

Model pengkorosian yang direncanakan dalam penelitian ini yaitu dengan mencelupkan specimen yang telah dilakukan proses perlakuan panas dengan 4 (empat) macam variasi temperatur, yaitu :

a. 1 spesimen dengan temperatur $600^{\circ} \mathrm{C}$

b. 1 spesimen dengan temperatur $700^{\circ} \mathrm{C}$

c. I spesimen dengan temperatur $800^{\circ} \mathrm{C}$

d. I spesimen dengan temperatur $900^{\circ} \mathrm{C}$

Specimen dalam hal ini mempunyai bentuk yang simetris yaitu berbentuk bujur sangkar dengan panjang sisi-sisinya yaitu $75 \mathrm{~mm}$ dan tebal 5 $\mathrm{mm}$.

3. Pengukuran berat setelah Pengkorosian

Setelah selama 24 jam (1 hari) logam baja dalam hal ini specimen uji AISI 304 dicelupkan ke dalam larutan kimia $\left(\mathrm{H}_{2} \mathrm{SO}_{4}\right)$ sebagai media korosi akan mengalami korosi, yang mengakibatkan berat logam specimen uji tersebut akan berkurang dari berat awal. Setelah 24 jam specimen uji tersebut dikeluarkan dari media korosi dan dilakukan pembersihan specimen serta dilakukan penimbangan.

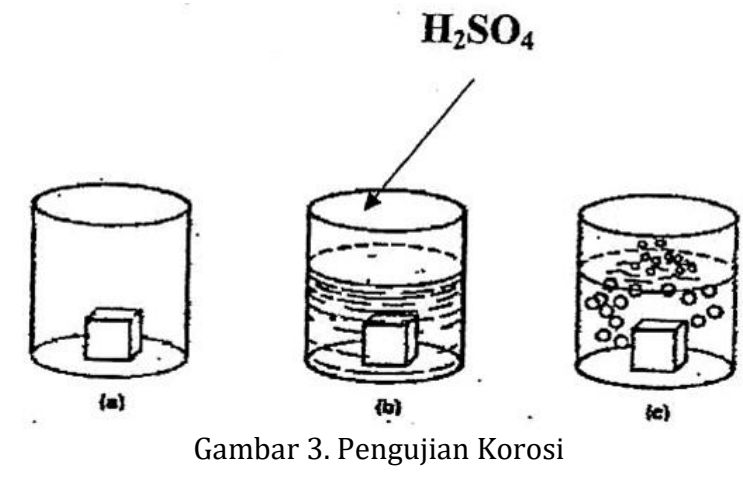

HASIL DAN PEMBAHASAN

\section{Hasil Pengamatan Struktur Mikro Pada Proses Heat Treatment}

Dari hasil perlakuan panas spesimen pada variasi temperatur dan holding time yang konstan yaitu 30 menit dan media pendinginan yang sama yaitu air, akan didapatkan struktur mikro yang berbeda-beda.

1. Spesimen 1

Spesifikasi : kondisi non heat treatment. Pembesaran 100x

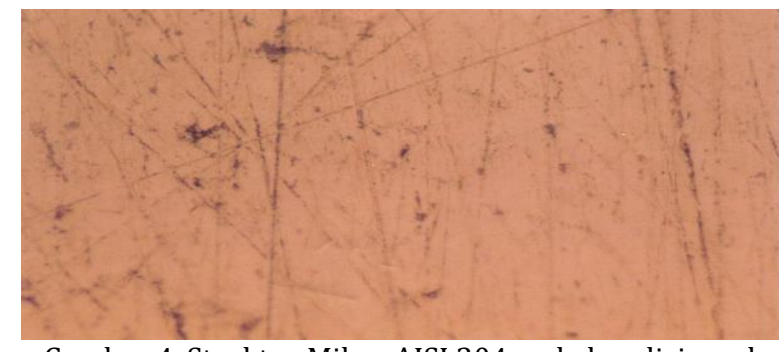

Gambar 4. Struktur Mikro AISI 304 pada kondisi awal (tanpa perlakuan panas dan tanpa media pendinginan). Pembesaran 100x

\section{Spesimen 2}

Spesifikasi : kondisi laku panas $\mathrm{T}_{1}=600^{\circ} \mathrm{C}$, holding time 30 menit, media pendingin air. Pembesaran 100x

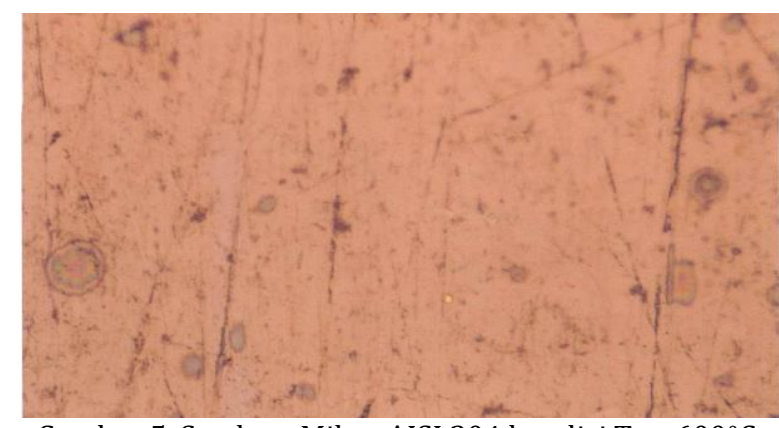

Gambar 5. Struktur Mikro AISI 304 kondisi $\mathrm{T}_{1}=600^{\circ} \mathrm{C}$, holding time 30 menit, media pendingin air. Pembesaran 100x.

\section{Spesimen 3}


Spesifikasi : kondisi laku panas $\mathrm{T}_{2}=700^{\circ} \mathrm{C}$, holding time 30 menit, media pendingin air. Pembesaran 100x

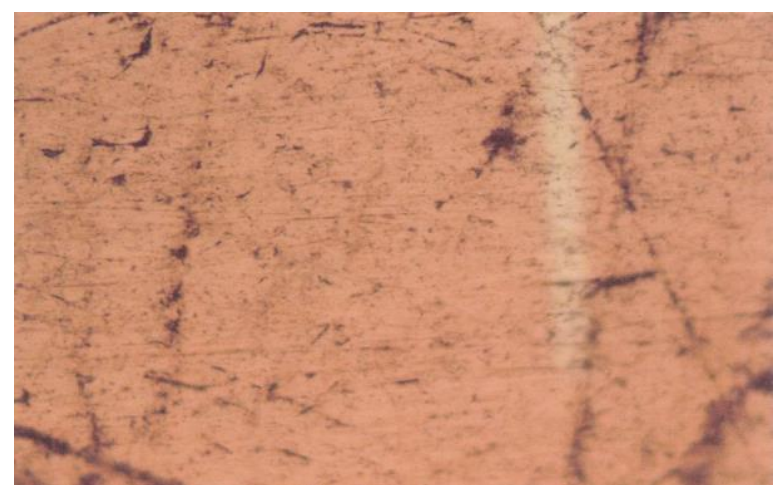

Gambar 6. Struktur Mikro AISI 304 kondisi $\mathrm{T}_{2}=700^{\circ} \mathrm{C}$, holding time 30 menit, media pendingin air. Pembesaran 100x.

4. Spesimen 4

Spesifikasi : Kondisi laku panas $\mathrm{T}_{3}=800^{\circ} \mathrm{C}$, holding time 30 menit, media pendingin air. Pembesaran $100 x$

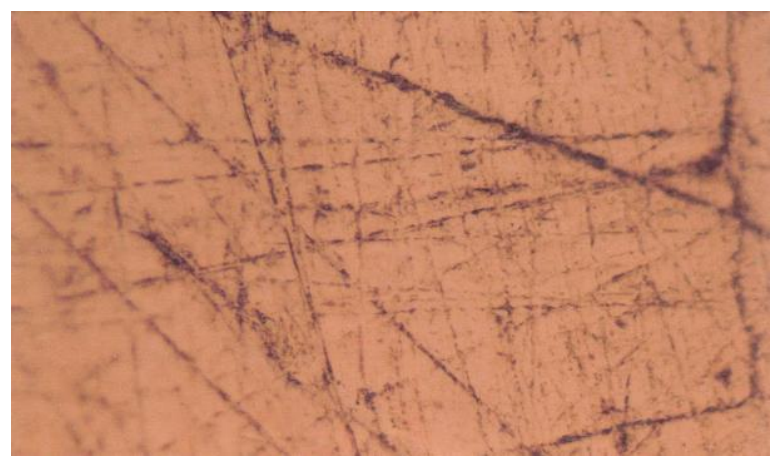

Gambar 7. Struktur Mikro AISI 304 kondisi $\mathrm{T}_{3}=800^{\circ} \mathrm{C}$, holding time 30 menit, media pendingin air. Pembesaran 100x.

5. Spesimen 5

Spesifikasi : kondisi laku panas $\mathrm{T}_{4}=900^{\circ} \mathrm{C}$, holding time 30 menit, media pendingin air. Pembesaran 100x

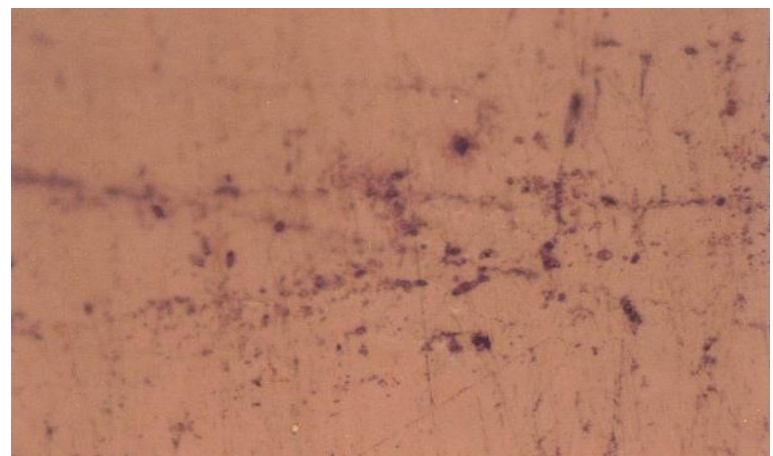

Gambar 8. Struktur Mikro AISI 304 kondisi $\mathrm{T}_{4}=900^{\circ} \mathrm{C}$, holding time 30 menit, media pendingin air. Pembesaran 100x.
Hasil Pengukuran Berat Setelah Proses Heat Treatment, Sebelum dan Sesudah Uji Korosi

Sebelum dilakukan pengkorosian material baja hasil proses heat treatment, baja dibersihkan dengan kertas gosok lalu ditimbang berat awalnya (Wo), dan didapatkan nilainya sebagai berikut. Setelah dilakukan pengkorosian dengan cara mencelupkan material baja ke dalam larutan asam sulfat $\left(\mathrm{H}_{2} \mathrm{SO}_{4}\right)$. Pencelupan tersebut dilakukan selama 1 hari. Kemudian baja diambil lalu dibersihkan terlebih dahulu dengan air biasa lalu ditimbang berat material baja tersebut (Wa), dan didapat hasil seperti pada Tabel 2 .

Tabel 2. Hasil pengukuran berat setelah proses uji korosi selama 24 jam dengan larutan $\mathrm{H}_{2} \mathrm{SO}_{4}$.

\begin{tabular}{|c|c|c|c|c|}
\hline No & Temperatur $\left({ }^{\circ} \mathrm{C}\right)$ & $\begin{array}{c}\text { Berat awal } \\
\text { Wo }(\mathrm{mg})\end{array}$ & $\begin{array}{c}\text { Berat akhir } \\
\text { Wa }(\mathrm{mg})\end{array}$ & $\begin{array}{c}\text { Selisih Berat } \\
\Delta \mathrm{W}(\mathrm{mg})\end{array}$ \\
\hline 1 & $\mathrm{NHT}$ & 227690 & 227680 & 10 \\
\hline 2 & $600^{\circ} \mathrm{C}$ & 226380 & 226300 & 80 \\
\hline 3 & $700^{\circ} \mathrm{C}$ & 229660 & 229570 & 90 \\
\hline 4 & $800^{\circ} \mathrm{C}$ & 235300 & 235150 & 150 \\
\hline 5 & $900^{\circ} \mathrm{C}$ & 213530 & 213310 & 220 \\
\hline
\end{tabular}

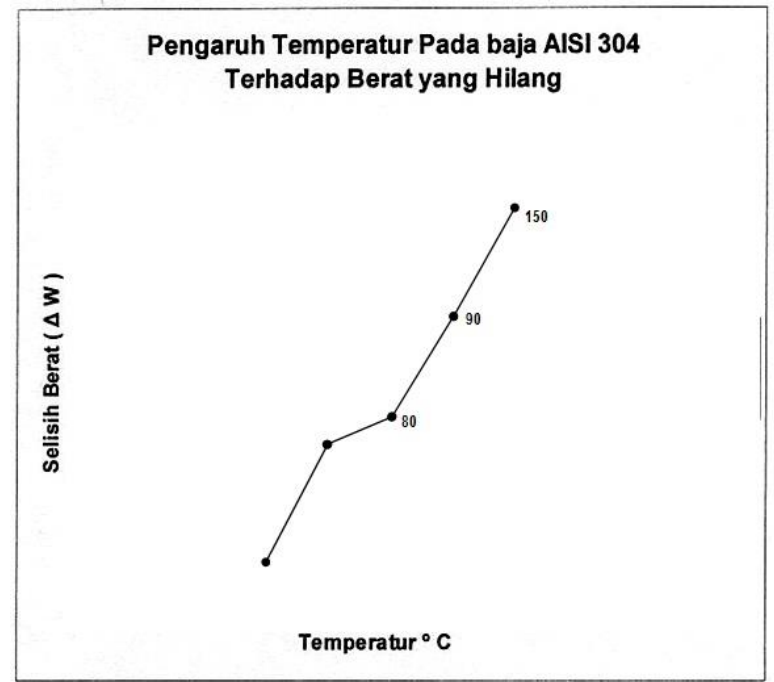

Gambar 9. Grafik pengaruh variasi temperatur terhadap berat yang hilang

Maka, dari data hasil pengukuran berat setelah dilakukan proses perlakuan panas dengan variasi temperatur akan didapat selisih berat setelah uji korosi miligram) sebagai berikut yaitu :

1. Pada kondisi Non Heat Treatment didapatkan $\Delta \mathrm{W}$ sebesar $10 \mathrm{mg}$

2. Pada temperatur $600^{\circ} \mathrm{C}$ didapatkan $\Delta \mathrm{W}$ sebesar $80 \mathrm{mg}$

3. Pada temperatur $700^{\circ} \mathrm{C}$ didapatkan $\Delta \mathrm{W}$ sebesar $90 \mathrm{mg}$

4. Pada temperatur $800^{\circ} \mathrm{C}$ didapatkan $\Delta \mathrm{W}$ sebesar $150 \mathrm{mg}$

5. Pada temperatur $900^{\circ} \mathrm{C}$ didapatkan $\Delta \mathrm{W}$ sebesar $220 \mathrm{mg}$ 


\section{Perhitungan Laju Korosi Pada Baja dengan Variasi Temperatur}

Dengan menggunakan rumus mpy (milli inch per year), yaitu :

$$
m p y=\frac{543 W}{D \cdot A \cdot T}
$$

dengan :

$W:$ berat yang hilang $\left(W_{0}-W a\right)$ dalam $\mathrm{mg}$

$D$ : masa jenis dalam $\mathrm{gr} / \mathrm{cm}^{3} \mathrm{U}$

Untuk baja AISI $304=0,29 \mathrm{lb} / \mathrm{in}^{3}=8.03 \mathrm{gr} / \mathrm{cm}^{3}$

$A$ : Luasan spesimen dalam in ${ }^{3}$

Luas yang dimaksud adalah luas keseluruhan dari spesimen yang tercelup, yaitu

$A=2(p \times 1)+2(p \times t)+2(1 \times t)$

$=2(2.95 \times 2.95)+2(2.95 \times 0.2)+2(2.95 \times 0.2)$

$=19.755 \mathrm{in}^{2}$

$T$ : lama pengkorosian dalam jam

Untuk pengkorosian ini dilakukan selama 24 jam

Tabel 3. Hasil pengukuran laju korosi setelah proses uji korosi selama 24 jam dengan larutan $\mathrm{H}_{2} \mathrm{SO}_{4}$.

\begin{tabular}{|c|c|c|c|}
\hline No & $\begin{array}{c}\text { Temperatur } \\
\left({ }^{\circ} \mathrm{C}\right)\end{array}$ & $\begin{array}{c}\text { Selisih Berat } \\
\Delta \mathrm{W}(\mathrm{mg})\end{array}$ & $\begin{array}{c}\text { mpy } \\
\text { (milli inchi per year) }\end{array}$ \\
\hline 1 & $\mathrm{NHT}$ & 10 & 1.40261163 \\
\hline 2 & $600^{\circ} \mathrm{C}$ & 80 & 11.2208931 \\
\hline 3 & $700^{\circ} \mathrm{C}$ & 90 & 12.6235047 \\
\hline 4 & $800^{\circ} \mathrm{C}$ & 150 & 21.0391745 \\
\hline 5 & $900^{\circ} \mathrm{C}$ & 220 & 30.8574559 \\
\hline
\end{tabular}

Maka hasil yang didapat tertera dalam Tabel 3. Dari tabel tersebut didapat hasil laju korosi sebagai berikut :

1. Pada temperatur $600^{\circ} \mathrm{C}$ didapatkan laju korosi sebesar $11.2208931 \mathrm{mpy}$.

2. Pada temperatur $700^{\circ} \mathrm{C}$ didapatkan laju korosi sebesar $12.6235047 \mathrm{mpy}$.

3. Pada temperatur $800^{\circ} \mathrm{C}$ didapatkan laju korosi sebesar $21.0391745 \mathrm{mpy}$.

4. Pada temperatur $900^{\circ} \mathrm{C}$ didapatkan laju korosi sebesar 30.8574559 mpy.

5. Pada Non heat treatment didapatkan laju korosi sebesar $1.40261163 \mathrm{mpy}$.

\section{PENUTUP}

Dari hasil pengamatan struktur mikro disimpulkan bahwa semakin tinggi temperatur pemanasan makin banyak korosi yang terjadi. Untuk AISI 304 tanpa perlakuan panas memiliki laju korosi yang lebih lambat dibandingkan dengan AISI 304 yang mengalami perlakuan panas. AISI 304 yang dikenai perlakuan panas, dengan temperatur lebih tinggi yaitu pada temperatur $900^{\circ} \mathrm{C}$ akan menyebabkan laju korosi lebih tinggi yaitu 30.8574559 mpy dan pada temperatur yang lebih rendah yaitu pada $600^{\circ} \mathrm{C}$ laju korosi paling lambat yaitu $11.2208931 \mathrm{mpy}$.

\section{DAFTAR PUSTAKA}

ASTM. (1986). Metal Test Metallurgy and Analytical Procedure, Vol 03.02. Philadelphia.

Fontana, M. G. (2005). Corrosion engineering. Tata McGraw-Hill Education.

Jones, D. A. (1992). Principles and prevention of corrosion. Macmillan.

Paret, R.E. (1978). Committee of Stainless Steel Producers. American Iron and Steel Institute. New York.

Sedriks, A.J. (1979). Corrosion of Stainless Steel. New York.

Surdia, T., \& Saito, S. (1999). Pengetahuan Bahan Teknik. Jakarta : Pradnya paramita.

Thelning, K.E., (1984). Steel and Its Heat Treatment. Second edition. London.

Zakharov, B. (1962). Heat Treatment of Metal. Moscow. 
D Perdana / Teknika, Vol. 1, No.1, Juni 2017, 67-72

Halaman ini sengaja dikosongkan 